\title{
Do low-cost ceramic water filters improve water security in rural South Africa?
}

\author{
Jens Lange ${ }^{1}$, Tineke Materne ${ }^{1}$, and Jörg Grüner ${ }^{2}$ \\ ${ }^{1}$ Hydrology, Faculty of Environment and Natural Resources, University of Freiburg, Freiburg, 79098, Germany \\ ${ }^{2}$ Forest Botany, Faculty of Environment and Natural Resources, University of Freiburg, \\ Freiburg, 79098, Germany
}

Correspondence to: Jens Lange (jens.lange@ hydrology.uni-freiburg.de)

Received: 7 July 2016 - Published in Drink. Water Eng. Sci. Discuss.: 11 July 2016

Accepted: 25 September 2016 - Published: 11 October 2016

\begin{abstract}
This study examined the performance of a low-cost ceramic candle filter system (CCFS) for point of use (POU) drinking water treatment in the village of Hobeni, Eastern Cape Province, South Africa. CCFSs were distributed in Hobeni and a survey was carried out among their users. The performance of 51 CCFSs was evaluated by dip slides and related to human factors. Already after two-thirds of their specified lifetime, none of the distributed CCFSs produced water without distinct contamination, and more than one-third even deteriorated in hygienic water quality. Besides the water source (springs were preferable compared to river or rain water), a high water throughput was the dominant reason for poor CCFS performance. A stepwise laboratory test documented the negative effects of repeated loading and ambient field temperatures. These findings suggest that not every CCFS type per se guarantees improved drinking water security and that the efficiency of lowcost systems should continuously be monitored. For this purpose, dip slides were found to be a cost-efficient alternative to standard laboratory tests. They consistently underestimated microbial counts but can be used by laypersons and hence by the users themselves to assess critical contamination of their filter systems.
\end{abstract}

\section{Introduction}

Within the last 25 years, 2.6 billion people have gained access to improved drinking water, while 663 million are still threatened by unsafe water from surface sources, unprotected springs or wells (WHO, 2015). Nearly half of the people without access to improved drinking water live in SubSaharan Africa and most of them in rural areas. In South Africa, for example, only $78 \%$ of the rural population had access to improved drinking water sources compared to $99 \%$ in urban areas, and over 3000 deaths due to unsafe water were estimated in 2012 (WHO, 2014).

In rural areas, decentralized water treatment systems provide opportunities to improve water security. Their efficiency against bacterial, viral and protozoan pathogens has widely been documented (e.g. Sobsey et al., 2008; Peter-Varbanets et al., 2009). Methods include application of heat or UV (boiling, solar radiation, UV lamps), chemical disinfection (e.g. by chlorine or silver), and physical removal by reverse osmosis or filtration (using activated carbon, granular media, membranes, ceramic cups or fibres). Advanced physical methods (like reverse osmosis or ultrafiltration) are safest and most efficient but largely limited to industrialized countries due to high investment costs. The first projects in developing nations installed them as small-scale systems supplying purified drinking water to entire villages or small communities. Modern stations can run on solar power and contain storage tanks for periods of unfavourable sunlight conditions (Sima and Elimelech, 2013; Elasaad et al., 2015). However, the treated water must still be transported and stored in households after treatment, which leads to a risk of recontamination (Gundry et al., 2006). Hence, point of use (POU) household water treatment may also contribute to water security in these cases. Among various methods, ceramic (CWF) and biosand (BSF) household water filters were identified as most effective (Brown, 2007; Sobsey et al., 2008). Murphy et al. (2010) monitored the microbiological and chemical qual- 
ity of treated water from BSF and CWF in rural Cambodia. During a 6-month period both technologies improved water quality for various parameters but failed to consistently meet the WHO drinking water guidelines for nitrite and for E. coli. BSF can be improved by using iron oxide coated sand (Ahammed and Davra, 2011) or by adding a layer of bark biomass (Ali Baig et al., 2011). Also, continuous operation resulted in better BSF performance (Young-Rojanschi and Madramootoo, 2014). Other studies concentrated on costefficient POU water treatment techniques. BSF with plastic housing was found to be as efficient as its concrete counterparts (Fabiszewski de Aceituno et al., 2012) and various researchers reported the success of locally produced, low-cost CWF (Brown et al., 2008; Simonis and Basson, 2011; Mwabi et al., 2013). Recent reviews of reduction of diarrhoea by different POU interventions found filtration techniques superior to solar or chemical water disinfection (Wolf et al., 2014; Clasen et al., 2015). However, comparisons were blurred by a high risk of bias, since the data relied on self-reported diarrhoea and placebo POU interventions were missing. For rural South Africa, low-cost ceramic water filters have been advocated for POU water treatment (Du Preez et al., 2008; Mwabi et al., 2013), and Du Preez et al. (2008) reported on their high acceptability. The need for improved drinking water supply in South Africa was recently manifested for two communities in the Municipality of Mutale (Rananga and Gumbo, 2015): $95 \%$ of the households were willing to pay for reliable drinking water supply; those with tertiary level education would afford ZAR 150 per month. However, Mellor et al. (2014) questioned the long-term efficiency of ceramic water filters under field conditions. Then human factors are crucial for POU water treatment, since regular maintenance and adequate cleaning are preconditions for microbial efficiency. As a consequence, a specific filter type that proved efficient in the laboratory might totally fail when distributed to rural communities and actually used under field conditions. This is particularly true for low-cost systems.

To prevent the failure of well-intentioned development projects, the efficiency of water filters should therefore continuously be monitored. Dip slides are a suitable way to comply with the need to frequently monitor aseptic conditions or treatment success of disinfection systems. Examples include the hygienic control of endoscopes in hospitals (Gerstenberger, 2008) or of cooling lubricants during processing of metals in mechanical engineering (Barth, 2003). Joyce et al. (1996) used dip slides under field conditions in Kenya to study the efficiency of water disinfection by solar heating, but did not document their reliability. Later, Sandhya et al. (1999) introduced dip slides as a robust, quick and costeffective method to qualitatively evaluate $E$. coli contamination down to concentrations of $10^{2}$ coliform units $(\mathrm{CFU}) \mathrm{L}^{-1}$ in water. Dip slides showed similar precision to swapping or contact agar plates during detection of contamination on artificially soiled stainless-steel surfaces (Salo et al., 2000). For drinking water, dip slides had considerably less accuracy

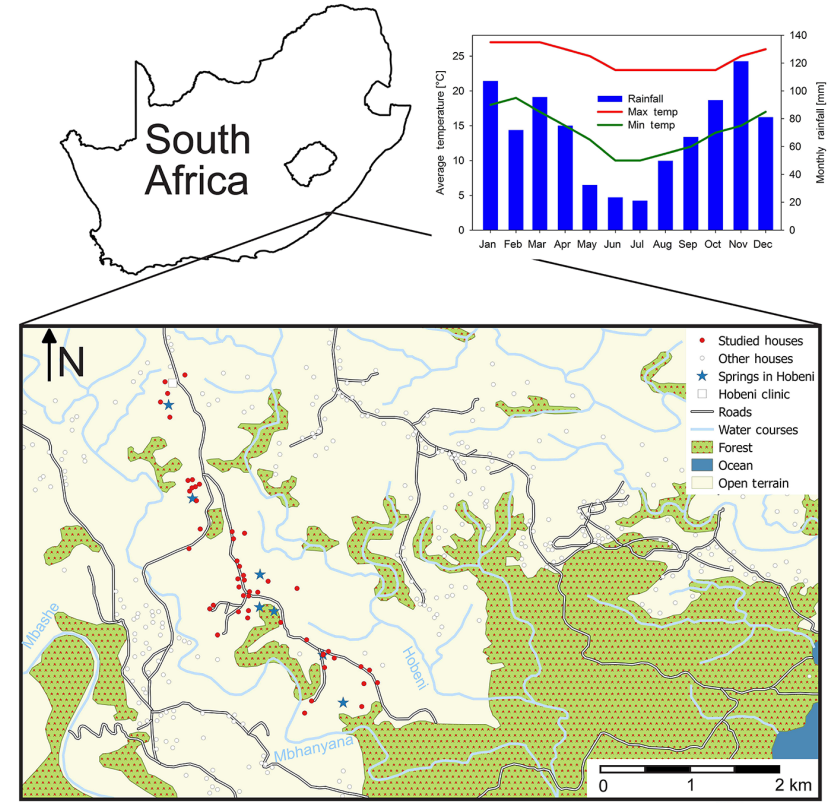

Figure 1. Location map and average climate.

than membrane filter methods but were recommended for the detection of massive contamination of drinking water sources (Vanderzwaag et al., 2009). Dip slides are much cheaper than standard laboratory tests and can also be used by unskilled personnel.

This study combined laboratory and field investigations to examine the efficiency of a widely used low-cost ceramic candle filter system (CCFS) for POU water treatment. The microbiological efficiency of the CCFS was examined by a stepwise laboratory test. In addition, CCFSs were distributed within a remote, rural area in South Africa and a survey was carried out among their users. Subsequently, CCFS performance was evaluated by dip slides after 8 months' use and related to human factors.

\section{Study area}

The study area is located in the village of Hobeni, Mbhashe municipality, which is situated in the south-eastern part of the Eastern Cape Province, South Africa (Fig. 1). Climate is temperate with $18.3^{\circ} \mathrm{C}$ mean temperature and annual rainfall of $1041 \mathrm{~mm}$. Mbhashe municipality is considered a remote, rural area with difficult conditions regarding water supply (Momba et al., 2006). About $50 \%$ of its inhabitants use untreated surface water from unprotected rivers or springs as their main drinking water source, $16 \%$ harvest rain water. During the study period, only one household of Hobeni village had access to treated water from communal water taps; none had its own groundwater well. 


\section{Methodology}

\subsection{The ceramic candle filter system (CCFS)}

We selected a widely used, low-cost (ZAR 599) two-bucket CCFS for our laboratory and field tests. It is commercially distributed under the brand name DrinC by Headstream Pure Water, Johannesburg, South Africa. It consists of the candle filter unit, wedged between two $20 \mathrm{~L}$ plastic buckets (Fig. 2). A tap is inserted at the base of the bottom bucket, which technically represents a safe storage container for drinking water according to local standards (CAWST, 2011). The ceramic filter candles consist of a $0.2 \mu \mathrm{m}$ silver-impregnated ceramic shell containing an activated charcoal interior medium. Lv et al. (2009) showed that silver nanoparticle-porous ceramic composites show efficient antibacterial effects without a measurable loss of nanoparticles. However, incorporated into water filters, Bielefeld et al. (2009) documented a significant wash-out of silver with decreasing filter efficiency. This process has to be taken into account for this type of water filter and per se causes a limited lifetime. Silver nanoparticles are widely used in various biomedical applications, although it is difficult to draw definite conclusions about their human and environmental toxicity (Wei et al., 2015). The filter candles of the studied CCFS have a diameter of $0.1 \mathrm{~m}$ and an unlimited shelf life (JustWater, 2016). Once in use, the candles have to be replaced once a year (DrinC, 2016). Raw water is filled into the top bucket of the CCFS. Water drips through the candle filter unit into the bottom bucket, where clean water can be drained through the tap. According to the manufacturer, CCFSs remove $>99.9 \%$ of harmful bacteria $(100 \%$ of $E$. coli), $>98 \%$ of particles larger than $0.2 \mu \mathrm{m},>96 \%$ of metals like $\mathrm{Fe}, \mathrm{Al}$, and $\mathrm{Pb}$, and $>80 \%$ of various organic pollutants. Users are advised to clean the filter every time the water flow becomes too slow. Then the bottom bucket should be cleaned by a bleach solution and the filter candle by a non-metal scrubbing pad. The main parts of the CCFS can be produced locally; only the filtering candles are imported from Europe or North America. In general, CCFSs have flow rates of approximately $1 \mathrm{Lh}^{-1}$, depending on the batch volume (CAWST, 2011). The specific CCFS tested in this study can reach rates of up to $4 \mathrm{~L} \mathrm{~h}^{-1}$ (Mwabi et al., 2013), making up approximately $40 \mathrm{Ld}^{-1}$. This volume can be regarded as adequate for an average household of six family members in Hobeni if a 3-4 L need for clean drinking water per person and day is assumed (Sawka et al., 2005).

\subsection{Dip slides}

Nutrient TTC-MacConkey (NUT/MAC) dip slides (Precision Laboratories, 2016) were used to study the performance of the CCFS under field conditions. They consist of a plastic paddle with different agar media on each side, covered by a plastic vial. Nutrient-TTC Agar supports the growth of a wide range of bacteria, while MacConkey Agar iden-

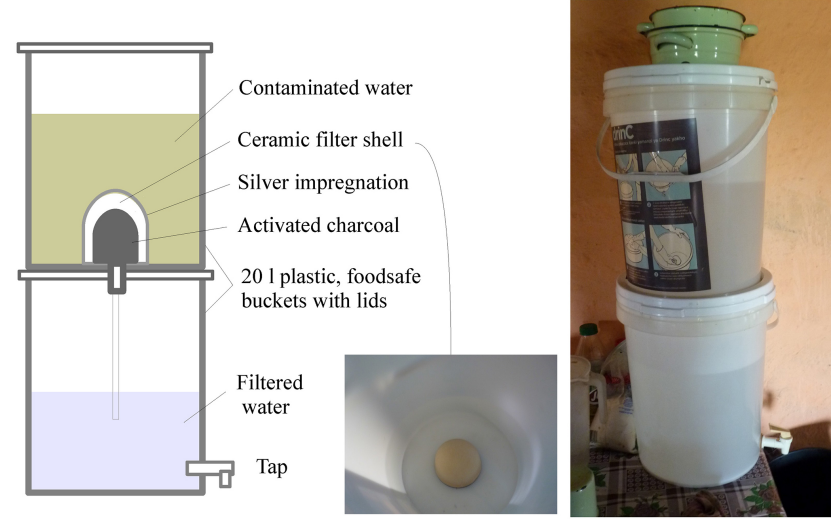

Figure 2. Technical layout of the tested CCFS.

tifies lactose-fermenting coliforms. For testing, the paddle is removed from the vial, dipped into the water for 15 to $20 \mathrm{~s}$, incubated for $24 \mathrm{~h}$ at $36 \pm 4^{\circ} \mathrm{C}$, and evaluated against colour charts provided by the manufacturer. Minimum precision is $10^{4} \mathrm{CFU} \mathrm{L}^{-1}$. An application software for mobile devices (BioPaddlesLite ${ }^{\circledR}$ ) has recently been published to evaluate dip slide readings with the help of standard images. The BioPaddlesLite $^{\circledR}$ software had not been available to be used in the present study.

\subsection{Stepwise laboratory performance tests}

Laboratory performance of the CCFS was evaluated in the hydrology laboratory of the University of Freiburg, which is accredited for microbiological drinking water analysis according to German DIN EN ISO standards. In these standards, E. coli bacteria are regarded as efficient indicators of faecal pollution (Paruch and Mæhlum, 2012). For CCFS performance tests they were used in reference solutions at concentrations of approximately from $10^{13}$ to $10^{16} \mathrm{CFU} \mathrm{L}^{-1}$. The top buckets of four CCFSs were filled with $20 \mathrm{~L}$ of tap water and spiked with $5 \mathrm{~mL}$ of reference solution. Background contamination was excluded by blank samples taken from the taps and the buckets. The initial bacterial concentration in the top buckets was evaluated by $100 \mathrm{~mL}$ samples taken by a sterile, graduated pipette. Testing started at ambient temperatures of $21^{\circ} \mathrm{C}$. The first laboratory protocol included a low filling scenario: the top bucket of the CCFS was filled once, and allowed to run for $48 \mathrm{~h}$ with $100 \mathrm{~mL}$ of filtrate collected from the bottom bucket after 7, 24, and $48 \mathrm{~h}$. During this $48 \mathrm{~h}$ period the top bucket was not filled up again. This was followed by a second laboratory protocol, which included a high filling scenario: during 3 days the top bucket was filled every day and $100 \mathrm{~mL}$ filtrate was sampled $7 \mathrm{~h}$ after each filling. Afterwards, the CCFSs were placed inside a laboratory incubator at $27^{\circ} \mathrm{C}$ to simulate field conditions and both high and low filling scenarios were conducted following the above protocols. Between all filling scenarios the 
CCFS buckets were rinsed with tap water and cleaned with a medical surface disinfectant. The collected samples were analysed by the membrane filter method according to German DIN EN ISO 9308 drinking water standards. In parallel, NUT/MAC dip slides were used.

\subsection{CCFS distribution and field survey}

In June 2014 a community meeting was hold in Hobeni, where the CCFS was described in detail and distributed among 150 rural households that showed interest. In January/February 2015, 91 households were visited during a 3-week period. The demographics of each household (number of adults/children living in the household, education of household members), the general acceptance of the CCFS (positive, negative) and aspects of maintenance and use (filling frequency, cleaning, water sources) were evaluated by a questionnaire. At 51 of the visited households water from the CCFS was able to be tested. The remaining 40 units did not contain enough water for the testing procedure and only the survey was conducted. CCFS performance was evaluated by comparing bacterial contamination of the top and bottom buckets by the NUT/MAC dip slides. In the top buckets the paddle was removed from the vial and dipped into the water for a contact time of 15 to $20 \mathrm{~s}$ with gentle stirring. The bottom buckets were tested by directly filling filtrated water from the CCFS tap into the dip slide vials that were subsequently tested by the paddles for 15 to $20 \mathrm{~s}$. After the tests, vials were emptied, and paddles and vials of all dip slides were closely linked, placed in a thermos bag and incubated after no more than $7 \mathrm{~h}$ at $36 \pm 4{ }^{\circ} \mathrm{C}$. For the incubation we used a cost-effective, portable, ventilated animal egg incubator with low energy consumption $(220 \mathrm{~V}-240 \mathrm{~V},<60 \mathrm{~W}$, ZJchao). The dip slides detected aerobic coliform bacteria as dots of a red-coloured dye. Ambient air temperature as well as temperature and electrical conductivity inside the CCFS buckets were measured by a PCE-PHD 1 portable conductivity meter (PCE Instruments).

\section{Results}

\subsection{Laboratory performance tests}

The first low filling scenario at $21^{\circ} \mathrm{C}$ ambient temperature resulted in $100 \%$ removal of the bacteria as detected by the membrane filter method (Fig. 3). Not a single coliform unit could be detected in the filtrate after 7, 24 and $48 \mathrm{~h}$. Also, the high filling scenario suggested satisfactory CCFS performance, although single coliform units were detected in the filtrate. However, during later tests at ambient temperature, typical for field conditions, no filtrate was free of coliform units and maximum values reached $5 \times 10^{3} \mathrm{CFUL}^{-1}$. Although removal rates were still above $99.99 \%$, these findings suggest that both the repeated loading and the higher ambient temperature affected CCFS performance. As a conse-

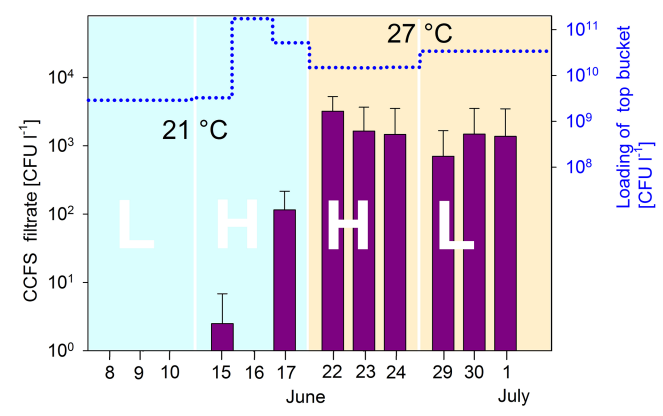

Figure 3. Stepwise laboratory performance tests. Blue dotted line: loading rates of the top buckets; bars denote the mean, errors bars the standard deviation of coliform counts in the filtrate of four replicates as detected by the membrane filter method; L stands for low, $\mathrm{H}$ for high filling scenario.

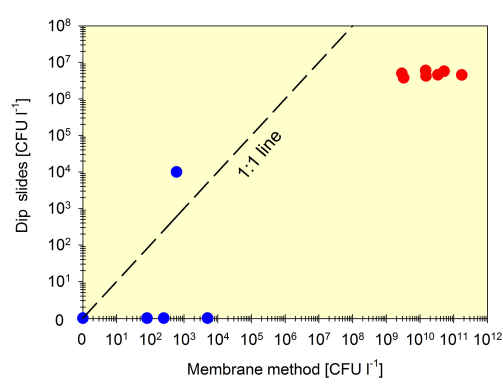

Figure 4. Comparison of dip slides with the accredited membrane method. Blue: samples of drinking water and bottom buckets during the final low filling scenario; red: samples of top buckets.

quence, the CCFS did not produce water that complied with international standards for drinking water (WHO, 2011). We fitted regressions to our data using the Generalized Linear Model with significance level $p<0.05$ for hypothesis testing. Those revealed no significant difference in different loading concentrations. The filling scenarios were influenced by repeated loading that had a significant influence on CCFS performance. Both the membrane method and the NUT/MAC dip slides attested to the microbial purity of the drinking water. Due to their limited precision, the dip slides detected contamination only in one out of four bottom buckets during the final filling scenario (Fig. 4). In the top buckets, the accredited membrane method yielded coliform counts $\left(2.8 \times 10^{9}-1.7 \times 10^{11} \mathrm{CFU} \mathrm{L}^{-1}\right)$ that were underestimated by the dip slides $\left(3.8-6.0 \times 10^{6} \mathrm{CFU} \mathrm{L}^{-1}\right)$. Although there was no clear linear relationship between the two methods, we did not obtain false positive dip slide readings.

\subsection{Field survey}

Hobeni is a small rural community with low average income. None of the 91 households that were visited had access to piped water in their own dwelling and only $26 \%$ to toilet facilities. The remaining $74 \%$ of the households were prac- 


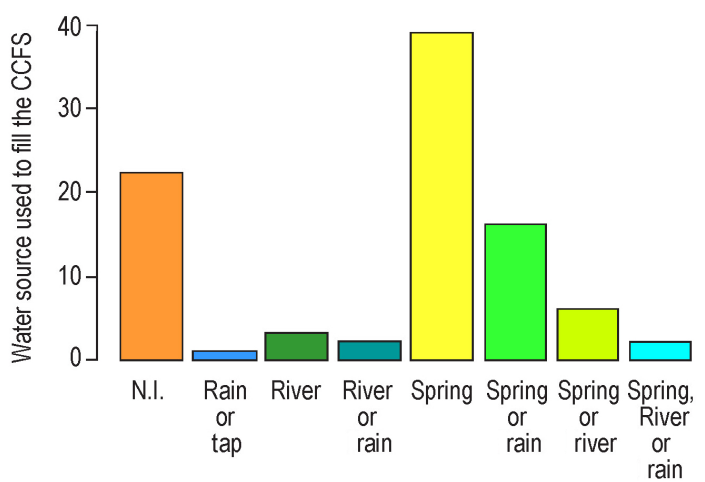

Figure 5. Water sources used for the filling of the CCFSs in 91 households.

ticing open defecation, which must be considered a serious threat to hygienic drinking water quality. This was one of the reasons why CCFSs were distributed in Hobeni. On average, households consisted of six people and used water from different sources to fill the CCFSs (Fig. 5). The acceptance of the CCFSs was generally high. Approximately 8 months after distribution, $69 \%$ (63 units) of the CCFSs were still in regular use, $20 \%$ (18 units) were broken and $5.5 \%$ (5 units) of the households refused to use the filters for different reasons. In $5.5 \%$ of the households (five units) the CCFSs were used only temporarily. The majority of the households $(60 \%)$ liked the clean water after the filtering procedure. Only $4.4 \%$ of the households complained about the intensive maintenance of the CCFS, $3.3 \%$ about the long distances to the water sources and only $1.1 \%$ about a slow filtering time. The majority ( $84 \%$ ) reported no incidents of digestive afflictions, including diarrhoea, in the family during the last 5 years. This was supported by an official statement by the Hobeni Clinic, although morbidity rates depend on self-reporting from the household members, which is known to produce substantial bias (Wolf et al., 2014; Clasen et al., 2015). Also, the microbiological water quality of 51 tested CCFSs showed contrasting results: none of the filtrate samples was free of coliform bacteria and $35 \%$ even showed a deterioration in water quality (Fig. 6). To evaluate the reasons for the CCFS failure in Hobeni, the CCFS efficiency was evaluated as a percentage of remaining coliform units in the filtrate and plotted against various household characteristics evaluated in the questionnaire survey. We excluded one outlier that showed a massive deterioration $(>1400 \%$; Fig. 6). All regressions showed a large scatter and $r^{2}$ values were below 0.1 , which precluded quantitative statistical analysis (Fig. 7). Nonetheless, the direction of the influence could visually be determined. Similar to the laboratory performance test, the ambient temperature showed an influence on CCFS efficiency. This was more prominent for water temperature inside the system than for ambient air. Only when the water temperature exceeded $21^{\circ} \mathrm{C}$ did some of the CCFSs deteriorate water quality. A second factor was the in-

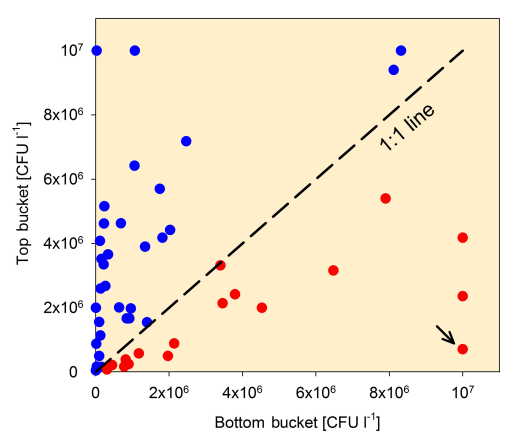

Figure 6. Coliform counts $\left(\mathrm{CFU} \mathrm{L}^{-1}\right)$ in $51 \mathrm{CCFS}$ systems sampled by dip slides in Hobeni village; red dots: water quality deterioration; arrow: outlier removed for further analysis.

tensity of CCFS use. This was evident from the filling frequency and from the numbers of people living in the households. Here the number of children had stronger effects on CCFS efficiency than the number of adults. More frequent cleaning could obviously not compensate for frequent CCFS use. A third factor was the water source: spring water apparently had higher quality. This could be traced by electrical conductivity, since values measured in CCFS only containing spring water $\left(0.27 \pm 0.13 \mathrm{mS} \mathrm{cm}^{-1}\right)$ were approximately double in those that were also filled by rain and river water $\left(0.13 \pm 0.14 \mathrm{mS} \mathrm{cm}^{-1}\right)$. While indoor keeping of animals showed a weak influence, our data did not suggest a positive effect of the educational level of CCFS users. Also, recommended bleaching did not improve CCFS performance.

\section{Discussion}

The dip slide testing method was chosen for field testing because of the lack of access to a laboratory in the remote study area. The commercial product we used was only sensitive to concentrations down to $10^{4} \mathrm{CFU} \mathrm{L}^{-1}$ and therefore not recommended for drinking water. On the one hand, this was corroborated by our laboratory test, where low CFU counts could not be detected. A consistent underestimation of dip slides is known (e.g. Kinneberg and Lindberg, 2002), which limits the quantitative evaluation of dip slide readings and also produced a large scatter in our data (Fig. 7). On the other hand, we did not obtain any false positive dip slide reading in our laboratory test. This makes NUT/MAC dip slides a valid compromise to assess the efficiency of drinking water treatment in our remote study area. We consider them appropriate to determine critical microbial presence in drinking water at minimal cost. They can directly be used in the households and in principle also directly by the CCFS users. New developments in free evaluation software for mobile devices will even increase their acceptance and reproducibility in future. Since only regular and repetitive monitoring guarantees the success of POU water treatment, we recommend that treatment systems should be accompanied by cost-efficient mon- 

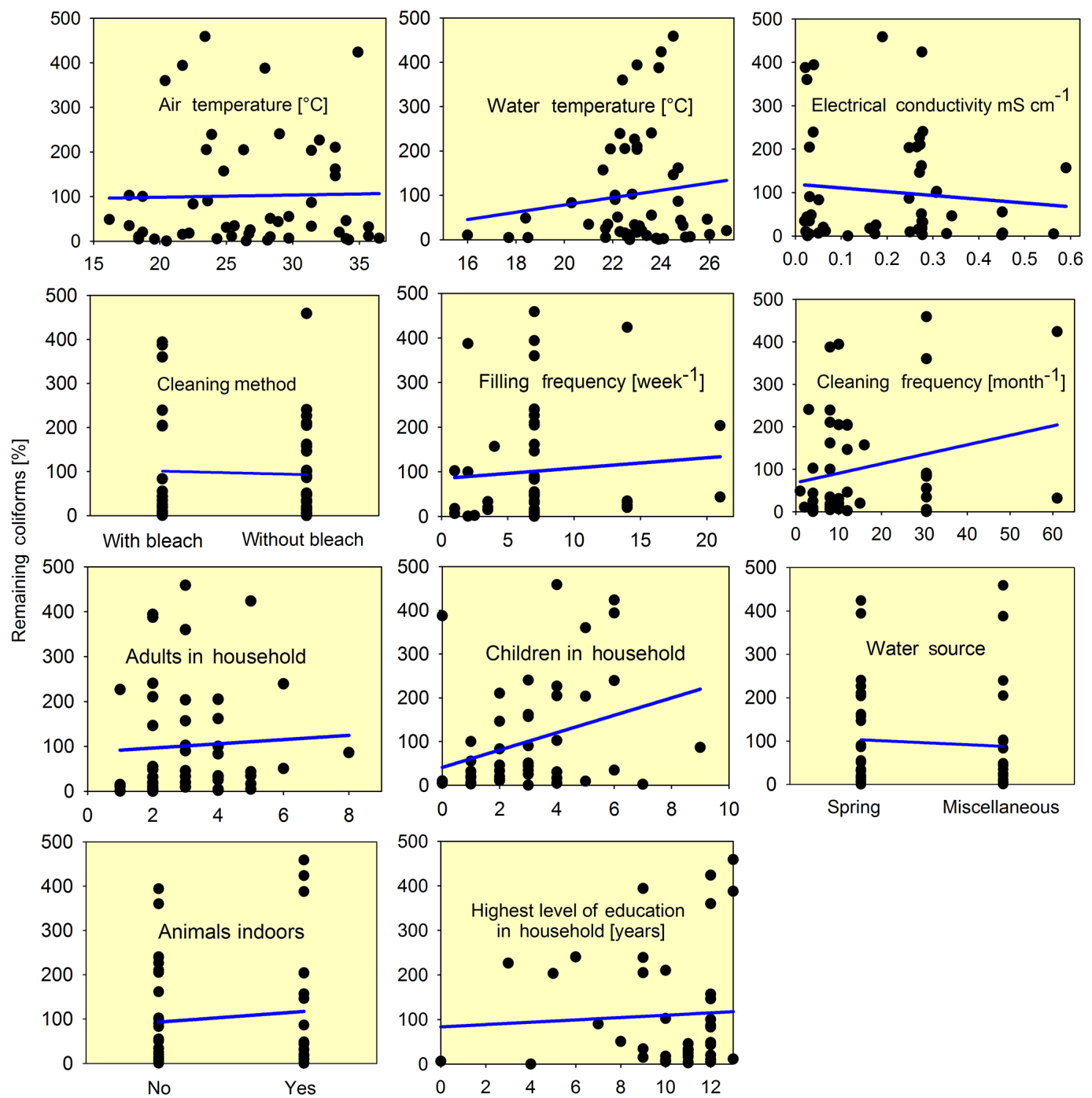

Figure 7. CCFS efficiency plotted against various factors included in the questionnaire; blue lines (linear regression) indicate the direction of influence.

itoring techniques where dip slides may be seen as a promising possibility.

Our 4-week laboratory tests (Fig. 3) suggested high removal efficiencies of the four investigated CCFSs that were in agreement with those found by Mwabi et al. (2013). However, since we used high loading, a removal rate of more than $99.9999 \%$ still resulted in up to $5 \times 10^{3} \mathrm{CFU} \mathrm{L}^{-1}$ in the filtrate. From a total of 45 filtrate samples only $16(36 \%)$ were free of bacteria, as required by international standards for drinking water (WHO, 2011). And those were collected during the first 8 days of our test. During later tests at an ambient temperature typical for field conditions, we observed considerably higher contamination of the filtrate. This means that our stepwise laboratory test actually reproduced both the impact of higher ambient temperatures and the gradual deterioration of CCFS performance. Bacteria are removed by
CCFSs mainly by physical retention inside the filter candle. Thereby, the silver impregnation of the ceramic shell supports the bacterial removal by antibacterial effects (Brady et al., 2003). However, it is known that silver can be washed out and that repeated loading of a CCFS will sooner or later cause lower removal efficiencies or even a bacterial colonization inside the filter candles (Bielefeldt et al., 2009).

With this in mind, the overall failure of the CCFS during the 8-month field test in Hobeni was no longer a surprise. Besides the water source (springs were preferable compared to river or rain water), our field data suggested that aging was the dominant reason for poor CCFS performance. Especially in households with many children and frequent filling of the CCFS, low bacterial removal rates were observed. More frequent cleaning even showed an opposite effect and apparently increased bacterial contamination of the filtrate. 
This indicates that the source of contamination is not only in the top or bottom buckets, but also inside the filter candle. We did not find clear evidence of effects of poor maintenance as noticed elsewhere (e.g. Brown, 2007; Mellor et al., 2014). This suggests that in Hobeni more intense teaching of CCFS use will probably not significantly improve the situation. We are aware that in addition to the qualitative nature of the dip slide readings, the uneven distribution of explaining factors limited the explanatory strength of our data. For example, the majority of households filled and cleaned the CCFS once a day and water temperatures mainly clustered in a range between 22 and $25^{\circ} \mathrm{C}$ (Fig. 7). Nevertheless, the documented effects of water source and temperature are logical and may thus be taken as a proof of the validity of our approach.

On the whole, our data suggest that the field performance of the investigated CCFS was not satisfactory. Although the duration of the test (8 months) was well below the specified lifetime of the CCFS candles (12 months), not a single dip slide indicated filtrate that was free of coliforms. Owing to the limited sensitivity of the dip slide method, this suggests massive contamination $\left(>10^{4} \mathrm{CFU} \mathrm{L}^{-1}\right)$ of all filtrate samples. On top of that, more than one-third of the CCFS caused deterioration of hygienic water quality. These findings contradict other field tests (e.g. Brown, 2007) and may thus be limited to the specific filter type we tested. However, our data suggest that not every CCFS is per se efficient and that each filter type needs a thorough check when distributed in the field.

\section{Conclusions}

This study shows that the performance of a specific, low-cost two-bucket ceramic candle filter system (CCFS) was not satisfactory for home-based water treatment in a remote rural community of southern Africa. A stepwise laboratory test documented the combined effect of repeated loading and ambient field temperatures. In the field, the distributed CCFS already failed after 8 months of use, representing only twothirds of its specified lifetime. Although users were taught how to handle and maintain the systems and the general acceptance was high, none of the distributed CCFSs produced water without distinct contamination. Besides the water source (springs were preferable compared to river or rain water) our data suggest that a high water throughput was the dominant reason for a poor CCFS performance. The fact that more than one-third of the investigated systems even deteriorated in water quality should be regarded as an alarming sign that systems used for household water cleaning should critically be tested. Our stepwise performance test (repeated loading first at low and then at typical field temperatures) is one possibility. If systems show a significant performance loss already during such tests, a satisfactory field performance should not be expected. But also in the field, the efficiency of any installed CCFS should contin- uously be monitored. Since the access to adequate laboratory facilities is usually restricted, dip slides may be regarded as a cost-efficient alternative to assess critical contamination even by laypersons and hence by the CCFS users themselves. Notwithstanding the obvious failure of the specific CCFS type evaluated in this study, it had a very high acceptance within the community, which motivates a follow-up study. Therein, alternative systems should be tested and their performance monitored on a monthly basis to also include seasonal changes in water quality. We also propose sanitation educational campaigns and behavioural change interventions to complement POU water treatment in Hobeni.

\section{Information about the Supplement}

The data of the laboratory performance test and of the field survey are included as supplementary files to this article.

\section{The Supplement related to this article is available online at doi:10.5194/dwes-9-47-2016-supplement.}

Acknowledgements. We express sincere thanks to all members, friends and donors of Tapini e.V. and the partner association Bulungula Incubator (BI) in South Africa, who made this study possible with a lot of personal effort in fund raising and the organizing of all logistics. Special thanks also go to all employees, residents and especially to Alexandra and Michael of Ikhaya Loxolo, who provided local accommodation. Liesl Benjamin helped a lot through cultural and linguistic mediation and massive physical effort during the time of field research in Hobeni. And finally, we thank the entire team of the hydrological lab at the University of Freiburg, especially Petra Küfner, for technical support and patience during the laboratory analysis.

Edited by: B. Mamba

Reviewed by: three anonymous referees

\section{References}

Ahammed, M. N. and Davra, K.: Performance evaluation of biosand filter modified with iron oxide-coated sand for household treatment of drinking water, Desalination, 276, 287-293, doi:10.1016/j.desal.2011.03.065, 2011.

Ali Baig, S., Mahmood, Q., Nawab, B., Shafqat, M. N., and Pervez, A.: Improvement of drinking water quality by using plant biomass through household biosand filter - A decentralized approach, Ecol. Eng., 37, 1842-1848, doi:10.1016/j.ecoleng.2011.06.011, 2011.

Barth, M.: Belastung und Beanspruchung durch biologische Arbeitsstoffe bei Kühlschmiermittel-Exponierten in der Metallbearbeitung, Dissertation, Heinrich-Heine-University Düsseldorf, Düsseldorf, 2003 (in German). 
Bielefeldt, A. R., Kowalski, K., and Summers, R. S.: Bacterial treatment effectiveness of point-of-use ceramic water filters, Water Res. 43, 3559-3565, doi:10.1016/j.watres.2009.04.047, 2009.

Brady, M. J., Lisay, C. M., Yurkovetskiy, A. V., and Sawan, S. P.: Persistent silver disinfectant for the environmental control of pathogenic bacteria, Am. J. Infect. Control, 31, 208-214, 2003.

Brown, J., Sobsey, M. D., and Loomis, D.: Local drinking water filters reduce diarrheal disease in Cambodia: a randomized, controlled trial of the ceramic water purifier, Am. J. Trop. Med. Hyg., 79, 394-400, 2008.

Brown, J. M.: Effectiveness of ceramic filtration for drinking water treatment in Cambodia, Dissertation, University of North Carolina, Chapel Hill, USA, 2007.

CAWST (Centre for Affordable Water and Sanitation Technology): Household Water Treatment and Safe Storage Fact Sheet, Calgary, Alberta, Canada, 2011.

Clasen, T. F., Alexander, K. T., Sinclair, D., Boisson, S., Peletz, R., Chang, H. H., Majorin, F., and Cairncross, S.: Interventions to improve water quality for preventing diarrhoea, Cochrane Db. Syst. Rev., 10, CD004794, doi:10.1002/14651858.CD004794.pub3, 2015.

DrinC: Instructions DrinC Water Bucket, http://drinc.co.za/ instructions/water-bucket, last access: 16 September 2016.

Du Preez, M., Conroy, R. M., Wright, J. A., Moyo, S., Potgieter, N., and Gundry, S. W.: Short Report: Use of Ceramic Water Filtration in the Prevention of Diarrheal Disease: A Randomized Controlled Trial in Rural South Africa and Zimbabwe, Am. J. Trop. Med. Hyg., 79, 696-701, 2008.

Elasaad, H., Biltonb, A., Kelley, L., Duayhe, O., and Dubowsky, S.: Field evaluation of a community scale solar powered water purification technology: A case study of a remote Mexican community application, Desalination, 375, 71-80, doi:10.1016/j.desal.2015.08.001, 2015.

Fabiszewski de Aceituno, A. M., Stauber, C. E., Walters, A. R., Meza Sanchez, R. E., and Sobsey, M. D.: A randomized controlled trial of the plastic-housing BioSand filter and its impact on diarrheal disease in Copan, Honduras, Am. J. Trop. Med. Hyg., 86, 913-921, 2012.

Gerstenberger, R.: Schnelltests zur Überprüfung einer erfolgreichen Aufbereitung bei Gastroskopen und Koloskopen, Dissertation, Charité-University of Berlin, Germany, 2008 (in German).

Gundry, S. W., Wright, J. A., Conroy, R., Du Preez, M., Genthe, B., Moyo, S., Mutisi, C., Ndamba, J., and Potgieter, N.: Contamination of drinking water between source and point-of-use in rural households of South Africa and Zimbabwe: implications for monitoring the Millennium Development Goal for water, Water Practice \& Technology 1, 1-9, doi:10.2166/wpt.2006.032, 2006.

Joyce, T. M., McGuigan, K. G., Elmore-Meegan, M., and Conroy, R. M.: Inactivation of fecal bacteria in drinking water by solar heating, Appl. Environ. Microb., 62, 399-402, 1996.

JustWater: 4" X4" Ceramic Filter, http://www.justwater.me/ products/4x4-ceramic-filter, last access: 16 September 2016.

Kinneberg, K. M. and Lindberg, K.: Dry Rehydratable Film Method for Rapid Enumeration of Coliforms in Food (3MTM Rapid Coliform Count Plate): Collaborative Study, J. AOAC Int., 85, 5671, 2002.

Lv, Y., Liu, H., Wang, Z., Liu, S., Hao, L., Sang, Y., Liu, D., Wang, J., and Boughton, R. I.: Silver nanoparticle-decorated porous ce- ramic composite for water treatment, J. Membrane Sci., 331, 5056, doi:10.1016/j.memsci.2009.01.007, 2009.

Mellor, J., Abebe, L., Ehdaie, B., Dillingham, R., and Smith, J.: Modeling the sustainability of a ceramic water filter intervention, Water Res., 49, 286-299, doi:10.1016/j.watres.2013.11.035, 2014.

Momba, M. N. B., Tyafa, Z., Makala, N., Brouckaert, B. M., and Obi, C. L.: Safe drinking water still a dream in rural areas of South Africa. Case Study: The Eastern Cape Province, Water SA, 32, 715-720, 2006.

Murphy, H. M., McBean, E. A., and Farahbakhsh, K.: A critical evaluation of two point-of-use water treatment technologies: can they provide water that meets WHO drinking water guidelines?, J. Water Health, 8, 611-630, doi:10.2166/wh.2010.156, 2010.

Mwabi, J. K., Mamba, B. B., and Momba, M. N. B.: Removal of waterborne bacteria from surface water and groundwater by costeffective household water treatment systems (HWTS): A sustainable solution for improving water quality in rural communities of Africa, Water SA, 39, 445-456, doi:10.4314/wsa.v39i4.2, 2013.

Paruch, A. M. and Mæhlum, T.: Specific features of Escherichia coli that distinguish it from coliform and thermotolerant coliform bacteria and define it as the most accurate indicator of faecal contamination in the environment, Ecol. Indic., 23, 140-142, doi:10.1016/j.ecolind.2012.03.026, 2012.

Peter-Varbanets, M., Zurbrügg, C., Swartz, C., and Pronk, W.: Decentralized systems for potable water and the potential of membrane technology, Water Res., 43, 245-265, doi:10.1016/j.watres.2008.10.030, 2009.

Presicion Laboratories: NUT/MAC Microslide - Technical Document, https://preclaboratories.com/wp-content/uploads/2015/01/ NUT.MAC_.INSTRUCTIONS-1.5.15.pdf, last access: 26 June 2016.

Rananga, H. T. and Gumbo, J. R.: Willingness to Pay for Water Services in Two Communities of Mutale Local Municipality, South Africa: A Case Study, Journal of Human Ecology, 49, 231-243, 2015.

Salo, S., Laine, A., Alanko, T., Sjöberg, A.-M., and Wirtanen, G.: Validation of the microbiological methods Hygicult dipslide, contact plate, and swabbing in surface hygiene control: A Nordic collaborative study, J. AOAC Int., 83, 1357-1366, 2000.

Sandhya, S., Uma, T. S., and Subbarao, K.: Dip Slide Technique for Rapid Qualitative Estimation of Fecal Coliforms in Water and Wastewater, Water Res., 33, 989-994, doi:10.1016/S00431354(98)00271-1, 1999.

Sawka, M. N., Cheuvront, S. N., and Carter, R.: Human Water Needs, Nutr. Rev., 63, 30-39, 2005.

Sima, L. C. and Elimelech, M.: More than a Drop in the Bucket: Decentralized Membrane-Based Drinking Water Refill Stations in Southeast Asia, Environ. Sci. Technol. 47, 7580-7588, doi:10.1021/es304384n, 2013.

Simonis, J. J. and Basson, A. K.: Evaluation of a low-cost ceramic micro-porous filter for elimination of common disease microorganisms, Phys. Chem. Earth, 36, 1129-1134, doi:10.1016/j.pce.2011.07.064, 2011.

Sobsey, M. D., Stauber, C. E., Casanova, L. M., Brown, J. M., and Elliott, M. A.: Point of Use Household Drinking Water Filtration: A Practical, Effective Solution for Providing Sustained Access to Safe Drinking Water in the Developing World, Environ. Sci. Technol., 42, 4261-4267, doi:10.1021/es702746n, 2008. 
Vanderzwaag, J. C., Bartlett, K. H., Atwater, J. W., and Baker, D.: Evaluation of Field Testing Techniques Used in a Household Water Treatment Study in Posoltega, Nicaragua, Water Qual. Res. J. Can., 44, 122-131, 2009.

Wei, L., Lu, J., Xu, H., Patel, A., Chen, Z.-S., and Chen, G.: Silver nanoparticles: synthesis, properties, and therapeutic applications, Drug Discov. Today, 20, 595-601, doi:10.1016/j.drudis.2014.11.014, 2015.

World Health Organization (WHO): Preventing diarrhoea through better water, sanitation and hygiene: exposures and impacts in low- and middle-income countries, World Health Organization, Geneva, Switzerland, 2014.

World Health Organization (WHO): Guidelines for Drinking-Water Quality, 4th Edn., Geneva, Switzerland, 2011.
World Health Organization (WHO): Progress on sanitation and drinking-water - 2015 update, World Health Organization and UNICEF, Geneva, Switzerland, 2015.

Wolf, J., Prüss-Ustün, A., Cumming, O., Bartram, J., Bonjour, S., Cairncross, S., Clasen, T., Colford, J. M., Curtis, V., De France, J., Fewtrell, L., Freeman, M. C., Gordon, B., Hunter, P. R., Jeandron, A., Johnston, R. B., Mäusezahl, D., Mathers, C., Neira, M., and Higgins, J. P. T.: Assessing the impact of drinking water and sanitation on diarrhoeal disease in low- and middle-income settings: systematic review and meta-regression, Trop. Med. Int. Health, 19, 928-942, doi:10.1111/tmi.12331, 2014.

Young-Rojanschi, C. and Madramootoo, C.: Intermittent versus continuous operation of biosand filters, Water Res., 49, 1-10, doi.:10.1016/j.watres.2013.11.011, 2014. 